\title{
Gene polymorphisms associated with susceptibility to coronary artery disease in Han Chinese people
}

\author{
Y.H. Liu' ${ }^{1}$, Y.W. Zhou ${ }^{1}$, J.A.Yang ${ }^{2}$, Z.G. Tu ${ }^{3}$, S.Y. Ji ${ }^{2}$, Z.Y. Huang ${ }^{2}$ and \\ Z.J. Zhou ${ }^{1}$ \\ ${ }^{1}$ Department of Laboratory Medicine, Sun Yat-sen Cardiovascular Hospital, \\ Shenzhen, Guangdong, China \\ ${ }^{2}$ Department of Cardiac Surgery, Sun Yat-sen Cardiovascular Hospital, \\ Shenzhen, Guangdong, China \\ ${ }^{3}$ Department of Laboratory Medicine, Chongqing Medical University, \\ Chongqing, China \\ Corresponding author: Y.W. Zhou \\ E-mail: yiwenzhou21@aliyun.com
}

Genet. Mol. Res. 13 (2): 2619-2627 (2014)

Received December 7, 2012

Accepted November 18, 2013

Published April 8, 2014

DOI http://dx.doi.org/10.4238/2014.April.8.4

\begin{abstract}
This study investigated 5 single nucleotide polymorphism (SNP) haplotypes in susceptibility genes for coronary artery disease (CAD) and the putative involvement of these SNPs in CAD in the Chinese Han population. From March 2008 to June 2009, we selected 119 CAD patients and 115 subjects not related to the CAD of Chinese Han origin as controls. The SNP genotypes were performed by multiplex SNaPshot technology. The HNRPUL1 gene rs11881940T and GATA2 gene rs3803T loci were highly correlated with CAD $(\mathrm{P}<0.05)$. rs10757278G increased the risk of CAD in patients indicated by an odds ratio (OR) $=1.242[95 \%$ confidence interval $(\mathrm{CI})=1.04-1.49]$; rs $11881940 \mathrm{~T}$ and rs3803T were protective factors for CAD with ORs $=0.767(95 \% \mathrm{CI}=$ $0.61-0.97)$ and $0.53(95 \% \mathrm{CI}=0.40-0.72)$, respectively. Analysis of the rs10757278, rs11881940 and rs3803 loci showed that haplotypes ATC
\end{abstract}


$(\mathrm{OR}=4.26 ; 95 \% \mathrm{CI}=2.85-6.40, \mathrm{P}<0.01), \mathrm{GAC}(\mathrm{OR}=1.50 ; 95 \% \mathrm{CI}=$ $1.25-1.81, \mathrm{P}<0.01)$ and $\mathrm{GAT}(\mathrm{OR}=1.53 ; 95 \% \mathrm{CI}=1.12-2.09, \mathrm{P}<0.01)$ were CAD risk factors, whereas GTC was protective $(\mathrm{OR}=0.48 ; 95 \% \mathrm{CI}$ $=0.32-0.72, \mathrm{P}<0.01)$. ATC and glucose were positively correlated (OR $=1.91 ; 95 \% \mathrm{CI}=1.01-3.61, \mathrm{P}<0.05)$. GAT was a risk factor for hypertension $(\mathrm{OR}=2.86 ; 95 \% \mathrm{CI}=1.40-5.83, \mathrm{P}<0.01)$. In conclusion, polymorphisms and haplotype analysis of susceptibility genes for CAD can improve predicting this disease and will enable early diagnosis of CAD.

Key words: Coronary artery disease; Predisposing genes; Polymorphism; Single nucleotide; Genotyping

\section{INTRODUCTION}

Coronary artery disease (CAD) is a complex malady and the leading cause of morbidity and mortality worldwide (Yusuf et al., 2001; Thom et al., 2006; Rosamond et al., 2007). Genetic and environmental factors interact with each other in CAD development and outcome. Genetic factors play a particularly important role in the pathogenesis of CAD and also in myocardial infarction (MI) (Topol et al., 2006). To date, many molecules and genes that play key roles in CAD have not been identified, and especially identifying the genetic risk factors for CAD requires further studies. It is generally accepted by the international community that $\mathrm{CAD}$ and other complex diseases are the result of the minor genetic differences that lead to cumulative effects. Indirect detection of gene function mutation and haplotype can be used to better understand the incidence of CAD and its underlying developmental mechanism at the molecular level, because their genetic profiles comprising multiple nucleotide polymorphism haplotypes are better models than single nucleotide polymorphisms (SNPs) in studies of genetic correlation with complex traits (Morris and Kaplan, 2002; Hoehe, 2003). To better understand whether gene variants are pathophysiologically relevant as precipitators of CAD and in other genotype-phenotype relationships, we report here a case-controlled association study in Chinese Han subjects. Selected genes such as the NPPA gene rs5063, the 9p21 regions rs10757274 and rs10757278, HNRPUL1 gene rs11881940, VAMP8 gene rs1010, GATA2 gene rs3803, and rs2713604, representing 7 loci were examined to determine whether genetic variants in these loci were associated with CAD. The aim of this study was to establish locus-specific contributions to the development of CAD within a selected Chinese Han population.

\section{MATERIAL AND METHODS}

\section{Study subjects}

All individuals included in this study were living in China. We carried out a casecontrolled association study involving 238 cases and 230 control volunteers that were selected from Sun Yat-sen Cardiovascular Hospital (Shenzhen, China) from March 2008 to June 2009. CAD diseases had been confirmed by clinical observations in patients' history, including echocardiography and imaging studies. Coronary angiography showed that at least 
one coronary artery vessel had $>70 \%$ luminal stenosis. Control volunteers mainly comprised healthy individuals and non-CAD patients whose past history of physical examination, imaging, and electrocardiography was used to exclude CAD diseases. The Han Chinese population that we selected was mainly from Henan, Hunan, and Guangdong Provinces. The individuals enrolled in this study were unrelated to each other, and written informed consent was obtained.

\section{DNA extraction and purification}

In total, 3-mL blood samples were collected at baseline from patients and controls and sodium citrate added to storage at $-70^{\circ} \mathrm{C}$. A DNA extraction kit was used to isolate and purify DNA from the blood samples.

\section{Primer design}

Each SNP site was used for designing 3 primers (Shanghai Health Workers); two of these primers with $\mathrm{Tm}$ value of about $60^{\circ} \mathrm{C}$ were used for amplification of target DNA fragments ranging 200-500 bp in length. Other primers were used for extension of ddNTP that was designed at the upstream of SNP sites or downstream of the reverse.

\section{PCR amplification}

Primers were diluted to $100 \mathrm{mM}$. PCR was performed with the following reagents: $1 \mu \mathrm{L}$ 10X buffer, $0.4 \mu \mathrm{L}$ primer $(10 \mathrm{mM}), 0.3 \mu \mathrm{L}$ dNTP $(10 \mathrm{mM}), 0.1 \mu \mathrm{L}$ HotStar enzyme (5 $\mathrm{U} / \mu \mathrm{L}), 1 \mu \mathrm{L}$ DNA, $0.52 \mu \mathrm{L} \mathrm{Mg}^{2+}(25 \mathrm{mM})$, and $6.68 \mu \mathrm{LddH}_{2} \mathrm{O}$ to a final volume of $10 \mu \mathrm{L}$. Multiplex reactions were performed using a PCR touch-down method for amplification. PCR products were analyzed by agarose gel electrophoresis, and successful PCR amplification assessed by the presence of bands of the predicted size.

\section{Purification of PCR products}

PCR products $(6 \mu \mathrm{L})$ and $2 \mu \mathrm{L}$ enzyme (including $2 \mathrm{U}$ SAP and $2 \mathrm{U}$ ExoI) were mixed by vortexing. This was followed by incubation at $37^{\circ} \mathrm{C}$ for $1 \mathrm{~h}$ and heating to $75^{\circ} \mathrm{C}$ for $15 \mathrm{~min}$. Purified DNA was stored at $4^{\circ} \mathrm{C}$ for $24 \mathrm{~h}$ or, for long-term storage, at $-20^{\circ} \mathrm{C}$.

\section{SNaPshot PCR template and purification of hybrid}

The PCR product was used as template in a micro-sequencing PCR (SNaPshot PCR). Each primer in the reaction had a final concentration of $0.2 \mathrm{nM}$. PCR cycling conditions were the following: 25 cycles of $96^{\circ} \mathrm{C}$ for $10 \mathrm{~s}, 50^{\circ} \mathrm{C}\left(53^{\circ} \mathrm{C}\right)$ for $5 \mathrm{~s}$; and $60^{\circ} \mathrm{C}$, for $30 \mathrm{~s}$, followed by one hold at $60^{\circ} \mathrm{C}$ for $30 \mathrm{~s}$ and storage at $4^{\circ} \mathrm{C}$. The SNaPshot PCR product in $5 \mu \mathrm{L}$ was added to $0.5 \mathrm{U}$ SAP or $1 \mathrm{U} \mathrm{CIP}$, mixed by vortexing, and incubated at $37^{\circ} \mathrm{C}$ for $1 \mathrm{~h}$, followed by $75^{\circ} \mathrm{C}$ for $15 \mathrm{~min}$ to inactivate the enzymes. Reacted samples were stored at $4{ }^{\circ} \mathrm{C}$ for $24 \mathrm{~h}$ or at $-20^{\circ} \mathrm{C}$ for long-term preservation. 


\section{Electrophoresis sample preparation and GeneMapper4.0 software analysis}

SNaPshot products $(1 \mu \mathrm{L})$ were prepared for electrophoresis in $9.25 \mu \mathrm{L}$ Hi-Di formamide and $0.1 \mu \mathrm{L}$ GS-120 LIZ, in a total volume of $10.35 \mu \mathrm{L}$; the mixture was then subjected to $95^{\circ} \mathrm{C}$ denaturation for $5 \mathrm{~min}$ and then rapidly cooled for $4 \mathrm{~min}$. Each electrophoresis sample was run with LIZ-120 internal standard, to accurately determine the sizes of fragments. The test results were analyzed by the GeneMapper4.0 software.

\section{Statistical analysis}

SNP genotypes and allele frequencies were determined with direct-counting methods. Haplotype analysis was performed using the PHASEv2.1 software. Continuous variables are reported as means \pm standard deviation. The following describes how statistical analyses were performed using the SPSS 13.0 package. Measurement data were compared between 2 groups using independent-sample $t$-tests. Allelic association of an SNP with a binary disease trait and some count data were assessed using Pearson $2 \times 2$-contingency table chi-square testing. Odds ratios $(\mathrm{OR})$ and $95 \%$ confidence intervals $(95 \% \mathrm{CI})$ were estimated using SPSS Ver 13.0. Multivariate logistic regression analysis was performed to test correlations of SNPs and haplotypes with CAD accounting for the significant covariates previously described (gender, age, hypertension, diabetes, and others). Empirical probability values were also calculated. AP $<0.05$ was considered to be statistically significant, and all $\mathrm{P}$ values were two-sided.

\section{RESULTS}

\section{Basic information of the study}

The body mass index of the control group was $<25 \mathrm{~kg} / \mathrm{m}^{2}$. Selected women were $>5$ years into menopause. To rule out that aging had an impact on CAD, the average age of the $\mathrm{CAD}$ group was younger than that of the control group $(\mathrm{P}<0.05)$. CAD and control groups were consistent with Hardy-Weinberg equilibrium $(\mathrm{P}<0.05)$. The $\mathrm{CAD}$ and control groups showed statistically significant differences $(\mathrm{P}<0.01)$ in blood pressure, pathoglycemia, smoking history, TC, TG, HDL, LDL, and other test results; gender and family history showed no significant differences between the two groups (Table 1).

\begin{tabular}{lccc}
\multicolumn{2}{c}{ Table 1. Basic information of the groups studied. } \\
\\
\hline Related factors & CAD group & Control group & P value \\
\hline Age (years) & $61.22 \pm 7.29$ & $63.55 \pm 6.52$ & 0.011 \\
Gender (male/female) & $186 / 52$ & $164 / 66$ & 0.088 \\
Hypertension & $174 / 238$ & $92 / 230$ & $<0.01$ \\
Glucose & $80 / 238$ & $22 / 230$ & $<0.01$ \\
Smoking history & $130 / 238$ & $68 / 230$ & $<0.01$ \\
Family history & 16 & $4.61 \pm 0.75$ & 0.428 \\
TC (mM) & $5.05 \pm 0.94$ & $1.37 \pm 0.59$ & $<0.01$ \\
TG (mM) & $1.76 \pm 0.82$ & $1.29 \pm 0.31$ & $<0.01$ \\
HDL (mM) & $1.14 \pm 0.32$ & $2.95 \pm 0.76$ & $<0.01$ \\
LDL (mM) & $3.38 \pm 0.96$ & $<0.01$ \\
\hline Age, TC, TG, HDL
\end{tabular}

Age, TC, TG, HDL, and LDL are reported as means \pm SD (comparison between the two groups was performed using an independent-sample $t$-test). Gender, blood pressure, pathoglycemia, smoking history, and family history ( $\chi^{2}$ test was used to compare). 


\section{CAD susceptibility gene loci}

The results of white blood plasma DNA genotyping in 238 cases and 230 controls showed that the 9p21 region rs10757278G and the HNRPUL1 gene rs11881940T and GATA2 gene rs3803T sites were highly correlated with $\mathrm{CAD}(\mathrm{P}<0.05)$. rs $10757278 \mathrm{G}$ increased the risk of CAD in patients as indicated by an $\mathrm{OR}=1.24(95 \% \mathrm{CI}=1.04-1.49)$; rs $11881940 \mathrm{~T}$ and rs $3803 \mathrm{~T}$ were protective factors for $\mathrm{CAD}$, with $\mathrm{ORs}=0.77(95 \% \mathrm{CI}=0.61-0.97)$ and 0.53 $(95 \% \mathrm{CI}=0.40-0.72)$, respectively. The results of our study further showed that the rs5063A, rs10757274G, rs1010G, and rs2713604A loci did not significantly correlate with CAD: ORs and $95 \% \mathrm{CIs}$ for these 4 loci were $1.10(0.71-1.67 ; \mathrm{P}>0.05), 1.17(0.98-1.40 ; \mathrm{P}=0.08), 1.18$ (0.95-1.47; $\mathrm{P}>0.05)$, and $1.12(0.54-2.29 ; \mathrm{P}>0.05)$, respectively (Table 2$)$.

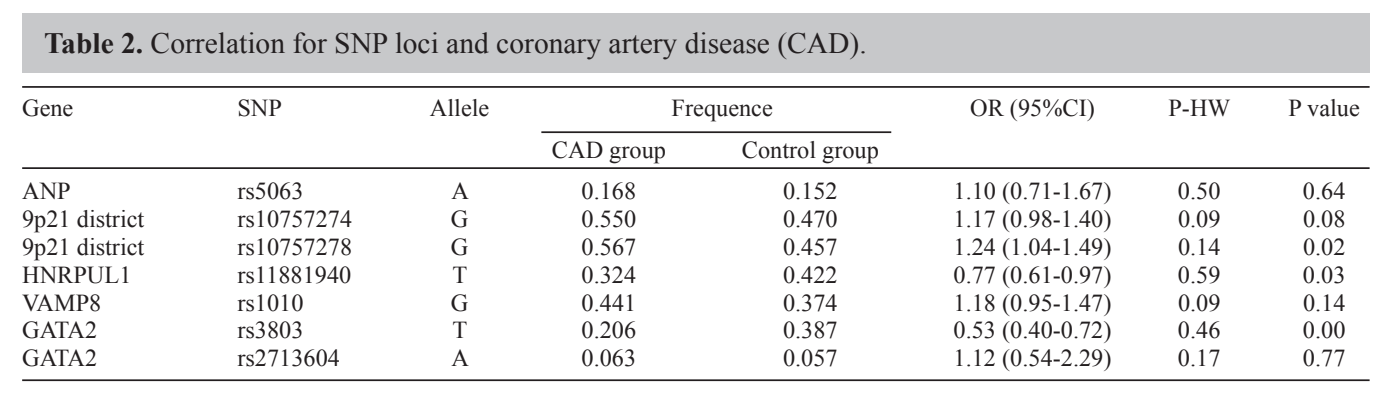

$\mathrm{P}-\mathrm{HW}=\mathrm{P}$ value for Hardy-Weinberg disequilibrium analysis; $\mathrm{OR}=$ odds ratio; $95 \% \mathrm{CI}=95 \%$ confidence interval.

\section{Haplotype analysis}

The PHASEv2.1 software was used to analyze the haplotypes of rs10757278, rs 11881940, and rs3803. This analysis showed that haplotypes ATC $(\mathrm{OR}=4.26 ; 95 \% \mathrm{CI}=$ $2.85-6.40, \mathrm{P}<0.01), \mathrm{GAC}(\mathrm{OR}=1.50 ; 95 \% \mathrm{CI}=1.25-1.81, \mathrm{P}<0.01)$, and $\mathrm{GAT}(\mathrm{OR}=1.53$; $95 \% \mathrm{CI}=1.12-2.09, \mathrm{P}<0.01)$ were all CAD risk factors. On the other hand, GTC was a protective factor for $\mathrm{CAD}$, indicated by an $\mathrm{OR}=0.48(95 \% \mathrm{CI}=0.32-0.72 ; \mathrm{P}<0.01)$ (see Table 3$)$.

Table 3. Susceptibility gene haplotype analysis of SNPs between the two groups.
\begin{tabular}{lcccc}
\hline Haplotype & CAD group (\%) & Control group (\%) & OR (95\%CI) & P value \\
\hline ATC & 44.5 & 10.4 & $4.27(2.85-6.40)$ & $<0.01$ \\
AAC & 40.3 & 45.2 & $0.89(0.72-1.10)$ & 0.286 \\
GTC & 12.6 & 26.1 & $0.48(0.32-0.72)$ & $<0.01$ \\
GAC & 61.3 & 40.9 & $1.50(1.25-1.81)$ & $<0.01$ \\
GAT & 31.9 & 20.9 & $1.53(1.12-2.09)$ & $<0.01$ \\
\hline
\end{tabular}

\section{Logistic regression analysis of CAD and its related factors}

Gender, hypertension, glucose, smoking history, family history, TC, TG, HDL, and LDL were all entered into a variable logistic regression model. This analysis indicated that male gender, hypertension, glucose, and TC were all highly relevant to CAD with adjusted ORs in the range of 3.00-6.07 ( $\mathrm{P}<0.05$; Table 4). A forward method based on partial likelihood ratios to the operational rules of gender, high blood pressure, pathoglycemia, smoking history, family history, TC, TG, 
HDL, and LDL gradually introduced these factors into a logistic regression model. The results of this analysis showed that male gender, hypertension, pathoglycemia, TC, and TG were highly correlated with $\mathrm{CAD}$ with adjusted ORs in the range of 1.89-7.74 $(\mathrm{P}<0.05$; Table 5).

Table 4. CAD-related factors and logistic regression analysis of all variables.
\begin{tabular}{lcccrr}
\hline Related factors & B & P value & OR & \multicolumn{2}{c}{$95 \%$ CI for OR } \\
\cline { 3 - 5 } & & & & Lower & Upper \\
\hline Gender & 1.80 & 0.00 & 6.07 & 2.57 & 14.31 \\
Hypertension & 1.10 & 0.00 & 3.00 & 1.44 & 6.23 \\
Pathoglycemia & 1.73 & 0.00 & 5.63 & 0.19 & 3.48 \\
Smoking history & 0.40 & 0.36 & 1.48 & 0.14 & 2.54 \\
Family history & -0.50 & 0.49 & 0.61 & 1.12 & 3.96 \\
TC & 1.26 & 0.03 & 3.51 & 0.91 & 1.91 \\
TG & 0.51 & 0.10 & 1.66 & 0.14 & 2.28 \\
HDL & -0.66 & 0.32 & 0.52 & 0.26 & \\
LDL & -0.25 & 0.65 & 0.78 &
\end{tabular}

Gender, high blood pressure, glucose, smoking history, family history, TC, TG, HDL, and LDL into all variable logistic regression model; B for the partial regression coefficient; OR for the introduction of the variable OR after correction.

Table 5. CAD-related factors and stepwise logistic regression analysis.
\begin{tabular}{lccccr}
\hline Related factors & B & P value & OR & \multicolumn{2}{c}{$95 \%$ CI for OR } \\
\cline { 3 - 5 } & & & & Lower & Upper \\
\hline Gender & 2.05 & 0.00 & 7.74 & 3.77 & 15.88 \\
Hypertension & 1.13 & 0.00 & 3.10 & 1.57 & 14.26 \\
Pathoglycemia & 1.74 & 0.00 & 5.67 & 2.25 & 3.99 \\
TC & 0.92 & 0.00 & 2.51 & 1.57 & 3.19 \\
TG & 0.64 & 0.02 & 1.89 & 1.12 & \\
\hline
\end{tabular}

Using forward stepwise (likelihood ratio) the gradual introduction of the rules of gender, high blood pressure, glucose, smoking history, family history, TC, TG, HDL, and LDL; B for the partial regression coefficient; OR for the introduction of the variable odds ratio after correction.

\section{Logistic regression analysis of haplotype and CAD-related factors}

Gender, hypertension, glucose, TC, TG, HDL, and LDL were also analyzed in a stepwise logistic regression model. In addition, haplotype ATC, GTC, GAC, and GAT were analyzed by logistic regression analysis to identify possible correlations with CAD. ATC and glucose results showed a positive correlation with $\mathrm{CAD}$ and had an $\mathrm{OR}=1.91(95 \% \mathrm{CI}=1.01-3.61, \mathrm{P}<0.05)$. GAT was a risk factor for hypertension with an $\mathrm{OR}=2.86(95 \% \mathrm{CI}=1.40-5.83 ; \mathrm{P}<0.01)$ (Table 6).

\begin{tabular}{|c|c|c|c|c|c|}
\hline \multirow[t]{2}{*}{ Haplotype } & \multirow[t]{2}{*}{ B } & \multirow[t]{2}{*}{ P value } & \multirow[t]{2}{*}{ OR } & \multicolumn{2}{|c|}{$95 \% \mathrm{CI}$ for OR } \\
\hline & & & & Lower & Upper \\
\hline \multicolumn{6}{|l|}{$\overline{\text { ATC }}$} \\
\hline Pathoglycemia & 0.65 & 0.05 & 1.91 & 1.01 & 3.61 \\
\hline \multicolumn{6}{|l|}{ GAT } \\
\hline High blood pressure & 1.00 & 0.00 & 2.86 & 1.40 & 5.83 \\
\hline
\end{tabular}

Using forward stepwise (likelihood ratio) rules of gender, high blood pressure, glucose, TC, TG, HDL, and LDL into stepwise logistic regression model; B for the partial regression coefficient; OR for the introduction of the variable odds ratio after correction. 
Gene polymorphisms associated with CAD

\section{DISCUSSION}

Genetic contributions to the risk of CAD are complex, and little attention has been paid to gene-environment interactions. Environmental modification results in heterogeneity of genetic effects and is increasingly recognized as a potential source of variability (Talmud, 2007).

The CAD study and control groups were consistent with Hardy-Weinberg equilibrium $(P>0.05)$. The two groups showed statistically significant differences $(P<0.01)$ in blood pressure, glucose, smoking history, TC, TG, HDL, and LDL. In contrast, no such differences were observed for gender and family history $(\mathrm{P}>0.05)$. The samples came from individuals of the Henan, Hunan, and Guangdong Provinces, who live a fast pace of life, face the pressure of survival, and have poor eating and lifestyle habits all of which can affect the incidence of CAD. On the other hand, other characteristics of these samples may also be relevant. When gender, hypertension, glucose, smoking history, family history, TC, TG, HDL, and LDL were all entered into a variable logistic regression model, male gender, hypertension, glucose, and $\mathrm{TC}$ were observed to be highly correlated with CAD. This analysis showed that these factors are highly relevant to $C A D$ with an adjusted $O R$ ranging from 3.00-6.06 $(\mathrm{P}<0.05)$, indicating that they are risk factors for CAD in the Chinese Han population.

Shen et al. (2008a), studying populations from South Korea, observed that the rs 10757274 and rs 10757278 alleles were highly correlated with CAD with ORs of 1.29 (95\%CI $=1.06-1.58)$ and $1.29(95 \% \mathrm{CI}=1.06-1.57)$, respectively. rs10757274 and rs 10757278 are located near the $C D K N 2 A$ and $C D K N 2 B$ genes, which encode proteins with important roles in the regulation of many cellular processes, including cell proliferation, maturation, senescence, and programmed cell death. However, there is no evidence that $C D K N 2 A$ and $C D K N 2 B$ have effects on the incidence of CAD (McPherson et al., 2007; Helgadottir et al., 2007). Virani et al. (2012) studying Caucasian subjects, observed that rs10757274 and rs 10757278 were not associated with recurrent MI and revascularization but that these two alleles may be associated with earlier development of more extensive disease. The results of studies conducted at a number of research centers and including different study populations have shown that rs $10757274 \mathrm{G}$ and rs $10757278 \mathrm{G}$ are associated with CAD. However, the mechanisms by which these alleles affect the incidence of CAD remain to be elucidated (Shen et al., 2008b; Ding et al., 2009; Scheffold et al., 2011). Some authors have suggested that these polymorphisms may impair the mechanical properties of the arterial wall and thus influence vascular diseases (Bjorck et al., 2009). In our study, rs10757274G was not significantly associated with CAD in the population we selected $(\mathrm{P}=0.08)$; this observation may be related to sample size and individual susceptibility. rs $10757278 \mathrm{G}$ was independently associated with an increased risk for the incidence of CAD. Shiffman et al. (2006) in a study of white Americans observed that the rs1010 locus in VAMP8, a gene involved in platelet degranulation $(\mathrm{OR}=1.75 ; 90 \% \mathrm{CI}=1.17-2.62 ; \mathrm{P}=0.025)$, and the rs11881940 site in HNRPUL1, a gene encoding ribonuclease $(\mathrm{OR}=1.92 ; 90 \% \mathrm{CI}=1.28-2.86$; $\mathrm{P}=0.0043$ ), were associated with early-onset MI (Gabler et al., 1998; Polgar et al., 2002). However, we found that the rs1010 locus was not significantly correlated with CAD, a result inconsistent with those reported by Duan et al. (2010), and this inconsistency may be due to differences in individual susceptibility to CAD. rs11881940T was observed to be a protective factor for $\mathrm{CAD}$; this allele may alter a conserved adenine in a putative interferon-regulatory factor-1-binding site, affecting the incidence of CAD.

Connelly et al. (2006), studying a Caucasian population, found that the alleles rs3803 and rs2713604 of the transcription factor GATA2 (Wang et al., 2007) were associated with 
CAD. We observed that rs3803 was a CAD-protective factor. rs2713604 was not significantly correlated with CAD, consistent with observations by Dandona et al. (2010) indicating that rs2713604 does not contribute to the development of CAD.

The results of our ABI PRISM ${ }^{\circledR} \mathrm{SNaPshot}^{\mathrm{TM}}$ genotyping analysis showed that the 9p21 region rs10757278G, HNRPUL1 gene allele rs11881940T, and the GATA2 gene allele rs3803T were highly correlated with CAD $(\mathrm{P}<0.05)$. rs $10757278 \mathrm{G}$ increased the risk of CAD in patients with an $\mathrm{OR}=1.242(95 \% \mathrm{CI}=1.038-1.487)$ and is an independent risk factor for CAD morbidity in Han Chinese people; rs $11881940 \mathrm{~T}$ and rs3803T were identified as CADprotective factors, indicated by $\mathrm{ORs}=0.767(95 \% \mathrm{CI}=0.605-0.973)$ and $0.532(95 \% \mathrm{CI}=$ 0.395-0.717), respectively.

Haplotype analysis of the rs10757278, rs11881940, and rs3803 loci showed that the haplotypes ATC, GAC, and GAT are risk factors for CAD and that GTC is a CAD-protective factor. Analysis of haplotype and CAD-related factors by logistic regression analysis showed that ATC was positively correlated with blood glucose abnormalities with an $\mathrm{OR}=1.912(\mathrm{P}<$ $0.05)$. On the other hand, GAT was significantly associated with hypertension (OR $=2.859 ; \mathrm{P}$ $<0.01$ ). The specific mechanisms responsible for these observations remain to be identified.

With the ongoing completion of the human genome haplotype map (the HapMap), studies of SNPs and haplotypes will certainly play an important role in identifying the underlying genetic mechanisms, the risk of incidence, and drug responses of CAD. But the major genes affecting the incidence and development of CAD still need to be identified, and the haplotypes need to be defined in terms of the number of SNP loci sufficient to explain the pathogenesis of CAD.

\section{ACKNOWLEDGMENTS}

Research reported by the Shenzhen Bureau of Science and by Technology Information Funded Projects (\#200701005).

\section{REFERENCES}

Bjorck HM, Lanne T, Alehagen U, Persson K, et al. (2009). Association of genetic variation on chromosome 9p21.3 and arterial stiffness. J. Intern. Med. 265: 373-381.

Connelly JJ, Wang T, Cox JE, Haynes C, et al. (2006). GATA2 is associated with familial early-onset coronary artery disease. PLoS Genet. 2: e139.

Dandona S, Chen L, Fan M, Alam MA, et al. (2010). The transcription factor GATA-2 does not associate with angiographic coronary artery disease in the Ottawa Heart Genomics and Cleveland Clinic GeneBank Studies. Hum. Genet. 127: 101-105.

Ding H, Xu Y, Wang X, Wang Q, et al. (2009). 9p21 is a shared susceptibility locus strongly for coronary artery disease and weakly for ischemic stroke in Chinese Han population. Circ. Cardiovasc. Genet. 2: 338-346.

Duan CC, Xu LX and Chen Q (2010). Association of the polymorphism of synaptobrevins/vesicle-associated membrane proteins 8 gene with coronary heart disease in Chinese Han population. Zhonghua Yi Xue Yi Chuan Xue Za Zhi 27: 329-332.

Gabler S, Schutt H, Groitl P, Wolf H, et al. (1998). E1B 55-kilodalton-associated protein: a cellular protein with RNAbinding activity implicated in nucleocytoplasmic transport of adenovirus and cellular mRNAs. J. Virol. 72: 79607971.

Helgadottir A, Thorleifsson G, Manolescu A, Gretarsdottir S, et al. (2007). A common variant on chromosome 9p21 affects the risk of myocardial infarction. Science 316: 1491-1493.

Hoehe MR (2003). Haplotypes and the systematic analysis of genetic variation in genes and genomes. Pharmacogenomics 4: $547-570$. 
McPherson R, Pertsemlidis A, Kavaslar N, Stewart A, et al. (2007). A common allele on chromosome 9 associated with coronary heart disease. Science 316: 1488-1491.

Morris RW and Kaplan NL (2002). On the advantage of haplotype analysis in the presence of multiple disease susceptibility alleles. Genet. Epidemiol. 23: 221-233.

Polgar J, Chung SH and Reed GL (2002). Vesicle-associated membrane protein 3 (VAMP-3) and VAMP-8 are present in human platelets and are required for granule secretion. Blood 100: 1081-1083.

Rosamond W, Flegal K, Friday G, Furie K, et al. (2007). Heart disease and stroke statistics - 2007 update: a report from the American Heart Association Statistics Committee and Stroke Statistics Subcommittee. Circulation 115: e69-171.

Scheffold T, Kullmann S, Huge A, Binner P, et al. (2011). Six sequence variants on chromosome 9p21.3 are associated with a positive family history of myocardial infarction: a multicenter registry. BMC Cardiovasc. Disord. 11: 9 .

Shen GQ, Li L, Rao S, Abdullah KG, et al. (2008a). Four SNPs on chromosome 9p21 in a South Korean population implicate a genetic locus that confers high cross-race risk for development of coronary artery disease. Arterioscler Thromb. Vasc. Biol. 28: 360-365.

Shen GQ, Rao S, Martinelli N, Li L, et al. (2008b). Association between four SNPs on chromosome 9p21 and myocardial infarction is replicated in an Italian population. J. Hum. Genet. 53: 144-150.

Shiffman D, Rowland CM, Louie JZ, Luke MM, et al. (2006). Gene variants of VAMP8 and HNRPUL1 are associated with early-onset myocardial infarction. Arterioscler Thromb. Vasc. Biol. 26: 1613-1618.

Talmud PJ (2007). Gene-environment interaction and its impact on coronary heart disease risk. Nutr. Metab. Cardiovasc. Dis. 17: 148-152.

Thom T, Haase N, Rosamond W, Howard VJ, et al. (2006). Heart disease and stroke statistics - 2006 update: a report from the American Heart Association Statistics Committee and Stroke Statistics Subcommittee. Circulation 113: e85-151.

Topol EJ, Smith J, Plow EF and Wang QK (2006). Genetic susceptibility to myocardial infarction and coronary artery disease. Hum. Mol. Genet. 15 (Spec. No. 2): R117-R123.

Virani SS, Brautbar A, Lee VV, MacArthur E, et al. (2012). Chromosome 9p21 single nucleotide polymorphisms are not associated with recurrent myocardial infarction in patients with established coronary artery disease. Circ. J. 76: 950-956.

Wang L, Hauser ER, Shah SH, Pericak-Vance MA, et al. (2007). Peakwide mapping on chromosome 3q13 identifies the kalirin gene as a novel candidate gene for coronary artery disease. Am. J. Hum. Genet. 80: 650-663.

Yusuf S, Reddy S, Ônpuu S and Anand S (2001). Global burden of cardiovascular diseases: Part I: general considerations, the epidemiologic transition, risk factors, and impact of urbanization. Circulation 104: 2746-2753. 